\title{
O CLIMA ORGANIZACIONAL FAVORÁVEL COMO VARIÁVEL NECESSÁRIA À GESTÃO DEMOCRÁTICA E PARTICIPATIVA
}

Data de aceite: 01/04/2021

Data de submissão: 15/03/2021

\section{Adriana Rodrigues de Melo Tavares}

Professora da Secretaria de Estado de Educação do Distrito Federal, Mestre em

Ciências da Educação/Administração Educacional pelo Instituto Politécnico de

Santarém, Técnica em Saneamento e

Educadora Ambiental da Companhia de Saneamento Ambiental do Distrito Federal Brasília - DF

\section{Márcia Lopes Reis}

Professora Assistente Doutor da UNESP na Faculdade de Ciências em Bauru, professora do Programa de Pós-Graduação em Educação

Escolar na UNESP/Araraquara e Professora Colaboradora do Programa de Pós-Graduação em Sociologia da Unicamp SP, Brasil São Paulo - SP

\section{Sónia Maria Gomes Alexandre Galinha}

Escola Superior de Educação - Instituto Politécnico de Santarém, PhD. em Psicologia,

Professora Adjunta da Escola Superior de Educação/Instituto Politécnico de Santarém, Portugal Santarém - Portugal

RESUMO: Este artigo, resultante de uma dissertação, traz considerações acerca da importância do clima organizacional favorável com vistas ao processo de gestão democrática e participativa. A pesquisa orientou-se pela abordagem em caráter qualitativo (entrevista semiestruturada) e quantitativo (questionário dentro da escala de resposta Likert), caracterizando assim, um estudo de caso misto. Nos resultados foram detectados pontos com oportunidades de melhoria, que podem auxiliar na implementação de avanços no processo de gestão democrática e participativa, reforçando a importância do ambiente organizacional como um de seus principais contributos. Nesse sentido, as conclusões apontam para a relevância dos estudos organizacionais, com ênfase no clima, como modalidade sujeita às mudanças além da própria cultura.

PALAVRAS-CHAVE: Clima Organizacional, Gestão Democrática e Participativa

\section{THE ORGANIZATIONAL CLIMATE FAVORABLE AS A VARIABLE NECESSARY TO DEMOCRATIC AND PARTICIPATORY MANAGEMENT}

ABSTRACT: This article, resulting from a dissertation, presents considerations about the importance of the favorable organizational climate with a view to the process of democratic and participatory management. The research was oriented by a qualitative (semi-structured interview) and quantitative approach (questionnaire within the Likert response scale), characterizing a mixed case study. In the results, points were identified with opportunities for improvement, which can help in the implementation of advances in the process of democratic and participatory management, reinforcing the importance of the organizational environment as one of its main contributions.

KEYWORDS: Organizational Environment, Democratic and Participatory Management. 


\section{INTRODUÇÃO}

A educação que se planeja hoje está respaldada no desenvolvimento da cidadania, da consciência coletiva voltada para o bem do ser humano, e de sua convivência pacífica e democrática com a natureza e com o próximo. Espera-se uma educação voltada para o desenvolvimento de competências que confiram ao indivíduo ferramentas adequadas para sua atuação num cenário globalizado. Partindo desta premissa, num cenário caracterizado pela integração, competitividade e qualidade, um grande desafio enfrentado pelos gestores se refere à administração do clima organizacional, e como deve ser a atuação dos líderes na busca de um ambiente que influencie de forma positiva a satisfação dos colaboradores.

A gestão democrática e participativa estabelece um ambiente produtivo e dialógico, cenário que segundo Freire (1981) destaca a essência da educação como prática da liberdade. Recentemente tem se observado, que práticas voltadas para a criação de uma parceria entre líderes e liderados num processo de gestão participativa tornam a empresa mais competitiva pela eficiência de suas ações e eficácia de suas operações. Tratando especificamente desse processo na escola, Veiga (1995) salienta que o processo de gestão democrática e participativa implica, necessariamente na ampla participação e interação dos representantes de diferentes segmentos das escolas nas decisões/ações administrativo pedagógicas ali desenvolvidas.

A escolha desse tema se justifica pela pertinência atual do assunto, uma vez que a educação e os seus intervenientes são pautas de tratativas constantes da sociedade em geral. O objetivo desse artigo analisar e refletir sobre a importância do clima organizacional como aspecto favorável e facilitador do processo de gestão democrática e participativa. Nesse sentido, dois conceitos são fundamentais nesse trabalho - são eles: clima organizacional e gestão democrática e participativa. O Quadro 1 sintetiza esses conceitos:

\section{Conceitos}

"É o conjunto de propriedades mensuráveis do ambiente de trabalho Clima organizacional percebido, direta ou indiretamente, pelos indivíduos que vivem e trabalham neste ambiente e que influencia a motivação e o comportamento das pessoas" Chiavenato (1997. p.126).

Gestão Democrática

e Participativa

"É o processo pelo qual se mobiliza e coordena o talento humano, coletivamente organizado, de modo que as pessoas possam promover resultados desejados" Luck (2009) (p.96).

Quadro 1: Conceitos Fundamentais

Fonte: Elaborado pela pesquisadora 


\section{REFERENCIAL TEÓRICO}

A gestão escolar mostra-se um processo de alta complexidade uma vez que o objetivo primordial da escola é formar cidadãos. Para alcançar esse objetivo há que se contar com a atuação de todos os atores envolvidos no processo educacional, pois esta visão e atuação configura a gestão participativa. Para melhor direcionar os distintos momentos e dilemas da prática educativa, pode-se contar com a análise do clima organizacional favorável como pano de fundo no processo de gestão democrática e participativa.

A análise do clima organizacional da escola fortalece a atuação do gestor no sentido de coordenar esforços individuais e coletivos em torno da consecução de objetivos comuns, definidos por uma política de ação, inspirada em uma filosofia que seja partilhada por todos e que agregue todos os atores envolvidos no "fazer educativo".

Clima organizacional segundo Luz (2003) é reflexo do estado de ânimo, ou do grau de satisfação dos funcionários de uma empresa num dado momento.

O clima é o indicador do grau de satisfação dos membros de uma empresa, em relação a diferentes aspectos da cultura ou realidade aparente da organização, tais como políticas de $\mathrm{RH}$, modelo de gestão, missão da empresa, processo de comunicação, valorização profissional e identificação com a empresa (p.11)

No processo educacional, a observância desse instrumento é essencial para viabilizar a gestão democrática. Em cada decisão tomada ou comunicação expedida, cada norma traçada ou reunião realizada entre dirigentes e dirigidos, o clima organizacional está num processo de permanente formação, sendo a resultante da complexa inter-relação do indivíduo e suas particularidades e os fatores externos ao mesmo.

Para que a escola possa se transformar continuamente, cumprindo sua missão institucional com eficácia e qualidade, necessita-se de um clima positivo, que é uma das variáveis essenciais à uma boa gestão; isto é, o gestor educacional que coloca em prática o diálogo entre os colaboradores da instituição, a participação da equipe nas decisões e prática a atribuição de responsabilidades tem maiores chances de promover um bom trabalho com sua equipe, tendo em vista melhores resultados.

Assim, em relação ao chamado clima organizacional, Chiavenato (2003) diz que "o nome de clima organizacional dado ao ambiente interno existente entre os membros da organização está intimamente relacionado com o grau de motivação de seus participantes" (p.106). Ainda sobre clima organizacional, no que tange à sua identificação como sendo favorável e desfavorável, Chiavenato (2004) descreve:

O clima organizacional é favorável quando proporciona satisfação das necessidades pessoais dos participantes e elevação do moral. É desfavorável quando proporciona a frustração daquelas necessidades, influencia o estado motivacional das pessoas e é por ele influenciada (p.75). 
A escola que vivencia a gestão democrática e participativa referendada por um clima organizacional favorável, encontra sua identidade e acompanha sua dinâmica de forma plena. Aprende-se muito com esse processo, uma vez que ele destaca a importância da vivência coletiva, do caminhar reflexivo, democrático, formativo e propenso para a democracia.

\section{METODOLOGIA}

O objetivo deste artigo refere-se a análise e reflexão da importância do clima organizacional favorável no processo de gestão democrática e participativa. A pesquisa foi orientada pela abordagem de observação mista, e caracterizou-se como estudo de caso por ter sido realizada em uma escola da rede de ensino do Distrito Federal. Partiu-se da revisão bibliográfica do tema quanto a importância da existência de um clima organizacional favorável contextualizando-o num cenário de gestão democrática e participativa. Paralelamente, foi feito um levantamento de dados por meio de entrevistas semiestruturadas realizadas com os gestores (diretora e supervisora pedagógica da escola), e aplicação presencial de questionários para o corpo docente, e administrativo da instituição.

Após análise distinta, foi feita uma triangulação dos dados coletados nas entrevistas com a diretora e supervisora pedagógica, assim como nos questionários aplicados aos servidores (docentes e assistentes administrativos em educação), buscando através dessa ação consolidar as conclusões a respeito do fenômeno investigado. Essa metodologia permitiu a obtenção de dados que foram observados por meio da "análise de conteúdo" Bardin (2016) bem como, conferiu ao processo de tabulação e análise dos dados obtidos um cenário com oportunidades de melhoria no que se refere ao objeto da pesquisa.

\section{Universo e público-alvo do estudo}

No âmbito da Rede Pública de Ensino, a Secretaria de Estado de Educação dispõe de uma estrutura regionalizada, composta por 14 Coordenações Regionais de Ensino - CRE, destinada a acompanhar diretamente as 724 unidades escolares e a, sobretudo, viabilizar o atendimento às especificidades da população em idade escolar dessas localidades. A escola pesquisada atende atualmente uma comunidade escolar de aproximadamente 1224 alunos, que são divididos entre $\circ 6^{\circ}$ ao $9^{\circ}$ anos do Ensino Fundamental - séries finais , matutino (406 alunos) e vespertino (364 alunos), e Educação de Jovens e Adultos - EJA (noturno) que compreende o $1^{\circ}$ segmento (99 alunos) até a $4^{\text {a }}$ etapa do ensino fundamental I, antiga $4^{\text {a }}$ série, e $2^{\circ}$ segmento (355 alunos), até a $9^{a}$ etapa do ensino fundamental II, antiga $8^{\mathrm{a}}$ série. $\mathrm{O}$ público do período noturno (ambiente pesquisado), é atendido por uma equipe que totaliza 38 pessoas, sendo que 23 estão em sala de aula, 3 atuam como coordenadores pedagógicos, 1 como supervisor administrativo, e 1 exerce o papel de supervisor pedagógico, a esse número soma-se ainda 4 servidores da área administrativa e outros 4 professores readaptados. 


\section{APRESENTAÇÃO E DISCUSSÃO DOS RESULTADOS}

Pretendeu-se por meio da análise das entrevistas e questionários aplicados, identificar as percepções dos gestores acerca da importância do clima organizacional favorável no processo de gestão democrática e participativa, identificar as ações voltadas à melhoria do clima organizacional promovidas pela equipe gestora, bem como analisar o grau de satisfação dos empregados com o ambiente de trabalho existente na escola. Destaca-se ainda que a entrevista semiestruturada foi realizada com a diretora e supervisora pedagógica da escola, e os dados obtidos foram tratados mediante análise de conteúdo Bardin (2016). Em relação ao questionário, sua aplicação teve como objetivo analisar a percepção dos servidores mediante o clima organizacional da instituição e sua influência no processo de gestão democrática e participativa, essa ferramenta de pesquisa foi elaborada a partir das orientações de Gil (2010) que afirma que esse, consiste em traduzir os objetivos específicos da pesquisa, devendo apresentar questões pertinentes face ao objeto e formuladas com clareza, de modo a serem facilmente compreendidas.

A análise do conteúdo das entrevistas foi organizada em categorias que incluíssem não só os temas tratados, mas as percepções dos gestores acerca da influência do clima organizacional favorável no processo de gestão democrática e participativa. As categorias eleitas foram gestão democrática e clima organizacional:

\begin{tabular}{ll}
\hline Conceitos \\
\hline Gestão democrática & Para Libâneo (2012) "a participação, o diálogo, a discussão coletiva, e a \\
& autonomia são práticas indispensáveis da gestão democrática" (p.454). \\
\hline Clima organizacional & $\begin{array}{l}\text { Teixeira (2005) define clima organizacional como percepções, opiniões e } \\
\text { sentimentos que são expressados pelo meio de comportamentos por um } \\
\text { grupo ou organização, em um dado momento. }\end{array}$ \\
\hline
\end{tabular}

Quadro 2: Categorias

Fonte: Elaborado pela pesquisadora

A partir da delimitação das categorias, observa-se que a força de trabalho da instituição pesquisada acredita que o clima organizacional favorável é um importante canal de diálogo, e uma estratégia possível para a materialização da construção democrática do processo que tem a educação como um dos pilares da cidadania. Dito isso, faz-se necessário destacar a observância dos conceitos.

\section{Gestão democrática}

A gestão democrática está calcada na participação, no diálogo coletivo, na escuta, na reflexão, na análise de conceitos, na criatividade, no espírito crítico, bem como na investigação das ideias propostas, na expansão do desejo de conhecer e compreender o mundo na busca de razões e fundamentos para um agir mais consciente, coerente e eficaz 
Libâneo, Oliveira e Toschi (2012). Através da gestão participativa, o cotidiano da escola se caracteriza como um espaço que deixa de ter um único líder, que decide e determina as ações pedagógicas, seus fins e resultados, para valorizar a troca de experiências e aquisição de conhecimentos entre todos os participantes escolares.

No que diz respeito ao entendimento de gestão democrática a entrevistada 1 demonstra o conhecimento do conceito quando afirma:

...numa direção, principalmente democrática...você muitas vezes tem que ceder, você não pode ser uma pessoa radical ... funciona assim trabalho em equipe, em grupo. ... tem que haver um consenso.

Ainda nesse sentido a entrevistada 2 destaca que:

Participação efetiva da comunidade escolar, ou seja, todos que estão envolvidos no processo educacional devem ser envolvidos na organização da escola, colaborando, opinando para que os projetos pedagógicos e físicos sejam alcançados com êxito.

De fato, para que uma gestão seja considerada democrática, é importante que toda equipe de servidores da instituição sinta-se parte do processo, cabendo ao gestor a missão de reforçar o modelo de participação na gestão versus gestão da participação. Compete a ele a ação de coordenar as relações entre todos os profissionais, alunos e a comunidade escolar, focando numa educação que permita uma relação democrática e participativa entre os envolvidos.

A gestão democrática é um estilo de administração capaz de socializar várias experiências, reunindo as pessoas em prol da conquista de objetivos comuns. Na escola, como em outras organizações, isso é importante, porque permite criar uma sinergia favorável à solução de problemas e ao despertar de inovações.

\section{Clima organizacional}

Nesse sentido, pontua-se que o clima organizacional, de acordo com Schein (1985) reflete o grau de satisfação pessoal com o ambiente interno da empresa, e está vinculado à motivação, à lealdade, à colaboração entre as pessoas, ao interesse no trabalho, à facilidade das comunicações internas, aos relacionamentos entre as pessoas, aos sentimentos e emoções e à integração da equipe e outras variáveis intervenientes. Nesse âmbito, as entrevistadas 1 e 2 consideram o clima organizacional um fator de desenvolvimento da gestão democrática, conforme trechos.

O clima organizacional é sim um fator de desenvolvimento da gestão democrática e participativa ... eu acho muito bom ... nós fazemos uma reunião onde nós discutimos as ideias, onde nós debatemos o que vamos fazer né? Se vem uma verba pra escola, é feita aquela reunião, a ata, nós apresentamos as prioridades que a escola, o que podemos fazer, e isso fica muito interessante porque todos participam, todos dão opinião. (entrevistada 1) 
É o clima positivo e o conhecimento do que é negativo que faz com que a empresaescola caminhe. (entrevistada 2)

Para George Litwin citado por Luz (2003) "clima organizacional é a qualidade ou propriedade do ambiente organizacional que é percebida ou experimentada pelos membros da organização e influencia o seu comportamento" (p.10).

Vários são os caminhos e estratégias para a efetivação da gestão democrática na Educação, sendo assim, nesse caminhar, há que se destacar que um ambiente laboral favorável propicia a satisfação das necessidades dos empregados afetando suas atitudes, despertando sua criatividade e a sua capacidade de adaptarem-se às mudanças. Dessa forma, entende-se necessário que a gestão democrática e participativa seja sensível ao clima existente na instituição, pois este conforme estudos, pode ser um valioso aliado, ou um implacável inimigo na atuação do gestor. Refletir sobre clima organizacional, implica na percepção dos valores internos e externos da instituição pois estes influenciam de forma direta o andamento das ações.

Sabe-se que a pesquisa, e análise de clima organizacional são tarefas árduas. No entanto, se fazem necessárias devido à riqueza de informações que o processo oferece. Os dados obtidos sendo devidamente tratados, aplicados e acompanhados em nível de excelência, auxiliam o gestor a atuar de forma holística considerando que o homem é um ser social, e único em suas particularidades. Com base nos depoimentos das entrevistadas, infere-se que gestores e educadores devem pautar suas ações na busca de um ambiente organizacional construtivo e agradável, fortalecido por princípios éticos e coletivos, que são de grande valia no processo de gestão democrática e participativa.

Ainda no processo de análise das ferramentas de investigação com foco na percepção dos servidores acerca de clima organizacional, bem como a sua influência no processo de gestão democrática e participativa, destaca-se que os questionários aplicados ao corpo docente, e administrativo da instituição foram inicialmente analisados sob o perfil quantitativo quanto à incidência das respostas, as quais posteriormente foram analisadas qualitativamente.

De acordo com os resultados, constatou-se que os colaboradores reconhecem a importância da existência de um bom clima organizacional no ambiente de trabalho, bem como o fato de que esse mesmo clima sofre interferências de acordo com o nível de satisfação da força de trabalho. Conforme Luz (2003) o clima organizacional nada mais é do que o reflexo do grau de satisfação dos funcionários da empresa em um determinado momento, capaz de criar oportunidade para crescimento e desenvolvimento ao possibilitar que as comunicações sejam objetivas, abertas e diretas gerando confiança interpessoal, divisão de poder e confrontação construtiva.

A consistência desse resultado demonstra que os entrevistados reconhecem a importância de um ambiente favorável na construção de um bom clima organizacional que priorize a prática de valores éticos, a participação coletiva como eixo central nas tomadas 
de decisões; assim como o incentivo constante ao diálogo, torna possível a criação de um ambiente que seja fértil e propício às mudanças positivas. No entanto, apesar desse entendimento os dados evidenciam que os servidores não estão satisfeitos com as estratégias, ações e reações desenvolvidas pela equipe gestora. É possível que essa insatisfação traga para os servidores a sensação de segurança no ambiente laboral, de impossibilidade de progresso profissional, além de impactar no desejo de participar de projetos que representem novas e positivas experiências no trabalho.

Ainda sob a ótica dos entrevistados, observa-se um nível considerável de concordância com relação à fragilidade do processo de comunicação interna entre os colaboradores e seus superiores, a inexistência de feedbackmostrou-se bastante significativa na visão dos servidores. Neste cenário, é importante salientar que a comunicação é uma das mais influentes ferramentas desse processo por meio da qual, grande parte dos problemas, bem como a resolução destes acontece. A retroalimentação recebida dos superiores influi diretamente nos níveis de satisfação e de motivação no trabalho dos subordinados. Um relacionamento autêntico entre líderes e liderados só pode ser construído quando se dá e se recebe feedback, pois cria um clima de relações humanas e compreensão mútua, bem como proporciona o controle dos objetivos pretendidos Torquato (1986).

Deste modo, os dados foram interpretados e discutidos, processo que permitiu a identificação das potencialidades, limitações e oportunidades de melhoria do clima organizacional com vistas à gestão democrática e participativa sob a ótica de gestores e servidores da escola pesquisada. Esse conjunto de informações sendo devidamente tratado, aplicado e acompanhado em nível de excelência, habilitam o gestor para atuar de forma holística considerando que a atividade de gestão é, essencialmente uma atividade humana, mas que ocorre de modo coletivo. No decorrer do processo de investigação e análise sobre os temas gestão democrática e participativa e clima organizacional, notamse algumas convergências e divergências sob a ótica dos pesquisados, dados registrados e apontados a seguir, esse detalhamento favorece maior compreensão clareza acerca do objeto de estudo.

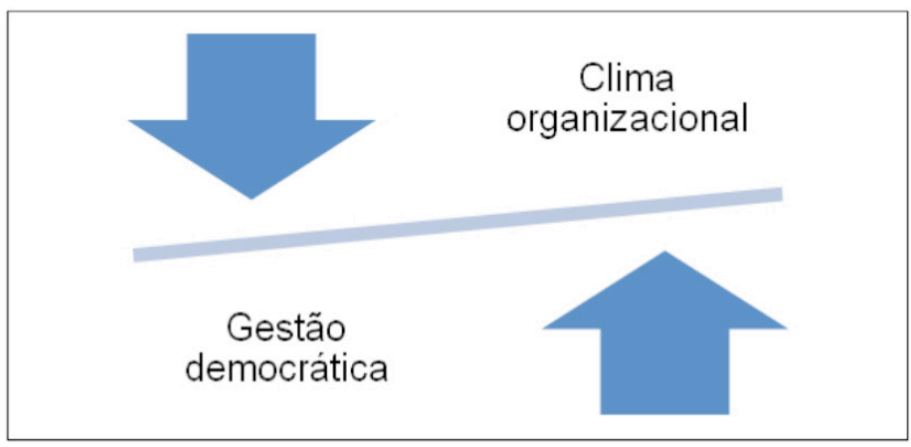

Quadro 2: Convergências e divergências

Fonte: Elaborado pela pesquisadora 
Liderar pessoas não é uma tarefa fácil, pois são seres de diferentes comportamentos, características, opiniões e culturas próprias que precisam estar alinhadas na busca do bem comum. É como ser maestro de uma orquestra em que os músicos têm liberdade para marcar seu próprio compasso na leitura da partitura. Nesse processo, identificar os pontos fortes e oportunidades de melhoria do processo de gestão torna-se essencial para a construção de relacionamentos sustentáveis. A seguir destaca-se alguns dos pontos observados durante a pesquisa entre líderes e liderados

\section{Convergências}

O clima organizacional é considerado por gestores e servidores como fator imprescindível para favorecimento da gestão democrática. Dito isso, vale salientar que o maior capital que uma escola possui são as pessoas, portanto, ao pensar e repensar suas práticas o gestor deve buscar a qualidade do clima organizacional, para que seja agradável e cooperativo, pois segundo Chiavenato (1994) as pessoas agem de acordo com as expectativas das outras, ao destacar essa percepção o gestor reflete entender a relevância da parceria íntegra no processo de tomada de decisão. Salientar e direcionar as potencialidades humanas no caminho sinuoso, porém compensador do alcance do bem comum é a condição prévia da educação. Em se tratando de parceria no processo de tomada de decisão voltada para o bem comum, os pesquisados apontam que a gestão democrática é a porta aberta para o diálogo, participação e valorização dos participantes da comunidade escolar, sendo a condição básica para que haja uma relação harmônica entre clima organizacional e gestão democrática, uma vez que a gestão do clima favorece a gestão democrática e vice-versa.

\section{Divergências}

O termo "gestão" segundo De Sordi (2005) compreende algumas fases como: planejamento, projeto, construção, implementação, utilização, monitoramento, identificação de melhorias e realização de ajustes. Para que se possa auferir a existência plena desse conceito é necessário atender cada uma dessa fases.

Observou-se durante a pesquisa que os pontos que suscitaram divergências foram clima organizacional e gestão democrática, precisamente os objetos de estudo deste trabalho.

Quanto ao clima organizacional em específico, há uma considerável divergência entre as gestoras. Enquanto uma considera adequado, outra mostra posição contrária, pontuando em sua fala situações que precisam ser melhoradas. Toro (2001) salienta que "clima organizacional são percepções compartilhadas e desenvolvidas por seus membros através das suas relações com as políticas, as práticas e os procedimentos organizacionais tanto formais quanto informais" (p.33).

No que se refere ao conceito e aplicação de gestão democrática, embora sua definição tenha sido observada e confirmada durante o levantamento e análise dos dados, 
destaca-se em alguns comentários presentes na coleta dessas informações, uma notória insatisfação dos servidores em relação às condições estruturais da instituição, bem como a descrença em expor sugestões, críticas e elogios, uma vez que não se sentem ouvidos. Esse cenário de incerteza e insatisfação favorece o surgimento de conversas informais que são extremamente prejudiciais ao processo.

Agir de forma proativa e sensível ao cenário existente caracteriza-se um dos grandes desafios da educação. Refletir sobre a prática é algo que vai além da identificação dos erros/ acertos e dos planos futuros, faz-se necessário um esforço em redirecionar, reorganizar e/ou readequar as diretrizes e ações com confiança e principalmente com o desejo de mudança, uma das características do processo democrático. Parafraseando Freire (1997) a democracia não é uma palavra vazia e sem sentido, ela precisa ser reconhecida e vivenciada em todo rigor que merece, uma vez que se configura como um dos pontos chave da educação, essa mesma educação traz consigo o poder de mudar as pessoas e essas, por sua vez mudam o mundo.

\section{CONSIDERAÇÕES FINAIS}

Com o aporte teórico apresentado e os dados acima citados da pesquisa pode-se perceber, que uma das características da gestão democrática e participativa é o incentivo ao clima organizacional favorável. De acordo com Luck (2001) a compreensão do conceito de gestão democrática pressupõe, em si, a ideia de participação, um trabalho associado de pessoas analisando situações, decidindo sobre seus encaminhamentos e agindo sobre elas coletivamente, tendo em vista que a existência de uma organização requer uma ação construtiva conjunta, por um trabalho associado, orientado por uma vontade coletiva.

Desafios sempre serão encontrados em práticas que oportunizam a participação, visto que há uma diversidade de concepções e opiniões acerca da participação no contexto escolar, portanto, a análise e tratamento adequado do clima organizacional é essencial para toda e qualquer instituição. Especificamente, no caso das instituições educativas que se propõem a implementar uma gestão democrática e participativa estruturada e bem fundamentada, esse contexto precisará ser vivenciado em sua prática pedagógica.

Nesse processo da vivência do clima organizacional favorável à gestão democrática e participativa, parece decisiva a disponibilidade de sujeitos envolvidos para que o caráter inovador se configure e ocorram as mudanças sugeridas. Neste sentido, Algarte (1991) destaca que as mudanças sociais passam, necessariamente, pela mudança individual. Daí a importância da conquista e manutenção, de um ambiente organizacional favorável na construção coletiva do processo de gestão democrática. Quando as pessoas sentem que fazem parte do contexto, que suas ideias estão agregadas ao processo, a tendência é de que este seja concretizado de forma mais consciente e dinâmica o que contribui para que a escola cumpra com as suas finalidades. 
Cabe salientar a importância da visão sistêmica da vida, onde o principal não é cada parte, mas "o todo" e como essas partes se inter-relacionam, sendo isso mais importante do que a soma das partes. Esse entendimento se fortalece na perspectiva de Delors (1999) que, por meio dos quatro pilares da educação, resultaria numa visão holística nutre o desenvolvimento da pessoa global e complexa, a qual deve ao longo da vida tirar o melhor partido de um ambiente educativo em constante ampliação.

Sem pretender esgotar o tema, acredita-se que estudos posteriores possam agregar novos conhecimentos acerca do tema abordado neste artigo, desde distintas perspectivas.

\section{REFERÊNCIAS}

ALGARTE, R. Planejamento na administração da educação nos diversos níveis do sistema: reflexões e propostas. RBAE, v.7, (1 e 2). jan./dez, 1991.

BARDIN, L. Análise de conteúdo. 70a Ed. São Paulo: Almedina, 2016.

CHIAVENATO, I. Administração de empresas: uma abordagem contingencial. $3^{a}$ ed. São Paulo: Makron Books, 1994.

CHIAVENATO, I. Gerenciando Pessoas. São Paulo: Makron Books, 1997.

CHIAVENATO, I. Administração de recursos humanos: fundamentos básicos. $5^{\text {a }}$ Ed. - São Paulo: Atlas, 2003.

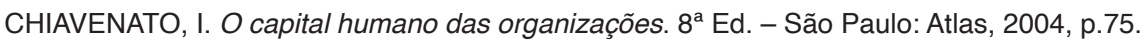

DELORS, Jacques. O Relatório está publicado em forma de livro no Brasil, com o título Educação: Um Tesouro a Descobrir (UNESCO, MEC). São Paulo: Cortez Editora, 1999. p. 89-102.

DE SORDI, J. O. Gestão por processos: uma abordagem da moderna administração. São Paulo: Saraiva, 2005.

FREIRE, P. Educação como Prática da Liberdade. São Paulo: Editora Paz Terra, 1981.

GIL, A. C. Como elaborar projetos de pesquisa. (5a ed.) São Paulo: Atlas, 2010.

LIBÂNEO, J. C., OLIVEIRA, J. F., TOSCHI, M. S. Educação Escolar: políticas, estrutura e organização. São Paulo, Cortez, 2012.

LUCK, H. Dimensões de gestão escolar e suas competências. Curitiba: Editora Positivo, 2009.

LUZ, R. Gestão do Clima Organizacional. Rio de Janeiro: Qualitymark, 2003, p.11.

SCHEIN, E. H. Career Anchors (Rev. Ed.), Trainer's Manual. San Diego: Pfeiffer, Inc., 1990, p.12; p.109-110. 
TORO, F. (2001). El clima organizacional. Perfil de empresas colombianas. Colômbia: Cincel, 2003, p.33.

TORQUATO, F. G. Comunicação empresarial, comunicação institucional: conceitos, estratégias, sistemas, estrutura, planejamento e técnicas. São Paulo: Summus, 1986, p.182.

VEIGA, I. P. Projeto político-pedagógico da escola: uma construção possível. Campinas: Papirus, 1995. 